\title{
Proton conducting electrolytes composed of chondroitin sulfate polysaccharide and citric acid
}

\author{
Filipe M. Santos ${ }^{a, *}$, Paula C. Barbosa ${ }^{b}$, Rui F.P. Pereira ${ }^{c}$, M. Manuela Silva ${ }^{c}$, \\ Helena M.R. Gonçalves ${ }^{\mathrm{a}, \mathrm{d}}$, Sílvia C. Nunes ${ }^{\mathrm{e}, \mathrm{f}}$, Filipe L. Figueiredo ${ }^{\mathrm{b}}$, Artur J.M. Valente ${ }^{\mathrm{g}}$, \\ Verónica de Zea Bermudez ${ }^{\mathrm{a}, *}$ \\ ${ }^{a}$ Department of Chemistry/CQ-VR, University of Trás-os-Montes e Alto Douro, 5001-801 Vila Real, Portugal \\ ${ }^{\mathrm{b}}$ Department of Materials and Ceramic Engineering/CICECO - Aveiro Institute of Materials, University of Aveiro, 3810-193 Aveiro, Portugal \\ ${ }^{\mathrm{c}}$ Chemistry Center and Chemistry Department, University of Minho, 4710-057 Braga, Portugal \\ ${ }^{\mathrm{d}}$ REQUIMTE, Instituto Superior de Engenharia do Porto, 4200-072 Porto, Portugal \\ ${ }^{\mathrm{e}}$ Chemistry Department, University of Beira Interior, 6201-001 Covilhã, Portugal \\ ${ }_{\mathrm{f}}^{\mathrm{f}}$ Department of Chemistry, University of Trás-os-Montes e Alto Douro, 5001-801 Vila Real, Portugal \\ ${ }^{\mathrm{g}}$ Chemistry Department, University of Coimbra, Coimbra, Portugal
}

\section{A R T I C L E I N F O}

\section{Keywords:}

Chondroitin sulfate

Biopolymer electrolytes

Ionic conductivity

Citric acid

\begin{abstract}
A B S T R A C T
Novel electrolytes composed of chondroitin sulfate A (CSA) and citric acid (CA) have been prepared using a clean, safe, and fast route. These electrolytes exhibit different physical-chemical properties, depending on the amount of CA. For $\mathrm{X}>82.3 \%$, where $\mathrm{X}$ is the mass ratio, in \%, of CA/(CA + CSA), whitish polycrystalline powders result. Lower amounts of CA leads to the production of translucent, amorphous films, sticky for $\mathrm{X}=75.6$ and 82.0, brittle for $\mathrm{X}<43.6$ and crack-free, self-standing for $43.6<\mathrm{X}<75.6 \%$. The results obtained provide evidence that, at low $\mathrm{pH}$, strong hydrogen bonding interactions take place between the anionic sulfonic and carboxylic groups of CSA and CA. CA exerts a key role, acting as a cross-linker and proton source, while simultaneously influencing sample morphology. At room temperature the highest ionic conductivity is achieved at $\mathrm{X}=60.8 \%$. A significant enhancement of the ionic conductivity of this sample occurs with the increase of relative humidity (RH) (from $3.1 \times 10^{-7}$ to $3.7 \times 10^{-2} \mathrm{~S} \mathrm{~cm}^{-1} 30 \%$ for $\mathrm{RH}=30$ and $\sim 100 \%$, respectively).
\end{abstract}

\section{Introduction}

According to the United Nations (UN), environmental and energy issues are two of the major challenges human society has to face. These problems have become so complex and taken on a global scale that, for the last decades, a call for game-changing technology that can lead to sustained development has consistently been issued [1]. In its latest iteration of the global sustainable development agenda, the UN has adopted 17 goals intended to prompt action from human agents in areas of critical importance for the sustained development of both human society and the planet [2]. Energy-wise, the UN goal aims to "ensure access to affordable, reliable, sustainable and modern energy for all" by focusing on three main areas: energy efficiency, renewable energy and energy access [2]. Access to reliable and sustainable energy sources has prompt the development of new technologies capable of addressing both the human need for energy as well as minimize the ecological consequences associated with its use. In this sense, the choice for chemistries that can minimize the ecological footprint and/or are easily integrated in a full circular economy needs to be prioritized.

In this context, biorenewable natural products, such as polysaccharides and proteins, are increasingly being held as ideal materials for the production of solid polymer electrolytes (SPEs), both from an economic and an environmental point of view [3-5]. The interest in SPEs $[6,7]$ has been steadily increasing, due to their applications in various solid state electrochemical devices, such as batteries, sensors, fuel cells, solar cells and electrochromic devices [8-11].

Polysaccharides are a versatile and rich family of macromolecules whose structure and thermodynamics have been extensively investigated. Polysaccharides comprise some of the most abundant biopolymers on Earth [5,12]. Polysaccharides, such as starch, heparin, cellulose, chitosan, hyaluronic acid or agar, among others, have been blended, doped, combined or otherwise manipulated with suitable

\footnotetext{
* Corresponding authors.

E-mail addresses: filipems@utad.pt (F.M. Santos), vbermude@utad.pt (V. de Zea Bermudez).
} 
substrates to produce ion conducting materials [12-19]. A popular strategy for the production of novel SPEs based on polysaccharide host polymers is to dope them with ionic liquids (ILs). The underlying objective is the combination of the polysaccharides' properties with other desirable properties present in the ILs, namely their high thermal stability, wide electrochemical potential window, moderate viscosity, good redox stability, plasticizing and lubricating properties $[13,14,20]$. However, ILs have been found to possess some disadvantages: (1) they may be more toxic than first expected [21-23] and (2) IL leakage problems have been reported [24]. These drawbacks motivated the development of another type of materials with physical properties and phase behavior similar to those of ILs. These materials, classed as deep eutectic solvents (DESs), possess a melting point lower than those of their individual constituents and low enough to be used as solvents. Because they are synthesized from eutectic mixtures of Lewis/Brønsted acids and bases derived from natural sources (e.g., aminoacids, carboxylic acids, sugars, urea and choline), DESs are economically cheaper and environmentally friendlier than conventional ILs [25-29].

Following our previous works on polysaccharide-based electrolytes $[13,14,31]$, we turned our attention to chondroitin sulfate (CS) as a potential SPE due to its anionic character and benign nature. CS is a naturally occurring linear polysaccharide (Fig. 1a) that is particularly abundant in the connective tissue of mammals, but also in invertebrates and even some bacteria. Similarly to what is found in the case of other biopolymers extracted from living organisms, CS chains exhibit significant structural variation in terms of molecular mass, arrangement of disaccharide units, sulfation pattern and charge density, among others $[32,33]$. However, all forms of CS share common structural features, including assemblages of disaccharide units mainly composed of $\beta(1,4)$ D-glucuronic acid and $\beta(1,3)-\mathrm{N}$-acetyl-D-galactosamine, incorporating hydroxyl, amide and carboxyl groups, and held together by glycosidic linkages (Fig. 1a) [32,33]. Sulfonic groups are often attached in either the C- 4 or C- 6 positions of the galactosamine residue. These two forms of CS are usually known as CSA and CSC, respectively. Other disaccharide sulfation patterns have also been reported which differ in terms of number (ranging from non-sulfated disaccharide units to disulfated disaccharides) or position (the second sulfonic group appearing in either the galactosamine residue or the glucoronic acid moiety). CS is known to be highly stable, hydrophilic, easily chemically modified, and exhibits low toxicity and good biodegradability [34]. Furthermore, electrolyte complexes can be formed with inorganic acids [35], metal cations [35] and cationic biopolymers, such as chitosan [36-40]. Curiously, until now, research conducted with this polyanion has been mostly restricted to therapeutic applications, such as tissue engineering $[34,41,42]$ and drug delivery $[39,41,43]$.

Inspired by the DES concept, we combined CSA with citric acid (CA)
(Fig. 1b), an organic polyprotic acid naturally occurring in citrus fruits. CA is known for its ability to establish hydrogen bonds [44] and form low-temperature transition mixtures (i.e. DESs) with other organic entities, namely choline, various sugars or proline $[30,45]$. Also of note is the increasing use of CA as a plasticizer $[46,47]$ and a cross-linker $[44,46]$, including in the preparation of proton exchange membranes [47]. A similar strategy was employed in the preparation of SPEs composed of chitosan and carboxylic acids, such as oxalic acid $[48,49]$, acetic acid [50] or maleic acid [16]. It is necessary to highlight that CSA has remained practically unexplored as a promising host polymer candidate for SPEs, in spite of the significant presence of sulfonic groups. Interestingly, just one work on the proton conductivity of a composite prepared from CSA, chitosan and hydroxyapatite was found in the literature [51]. The proton conductivity values registered by this composite are higher than those reported for Nafion [51].

The SPEs here described were synthesized by means of a clean, safe and cheap procedure, and their structure, thermal and electrochemical properties were investigated. These electrolytes will be henceforth noted as CA:CSA $(\mathrm{X})$, where $\mathrm{X}$ is the mass ratio, in $\%$, of $\mathrm{CA} /(\mathrm{CA}+\mathrm{CSA})$ $(15.2 \leq \mathrm{X} \leq$ 93.7).

\section{Materials and methods}

\subsection{Reagents and synthetic procedures}

Chondroitin sulfate A, sodium salt (CSA, 90\% pure, Alfa Aesar lot.: 61301303), and anhydrous citric acid (CA, 99.5+\% pure, grade ACS, ISO. Reag. Ph. Eur, Merck, Inc) were used as received. Distilled water was used throughout all experiments.

In a typical experiment, a solution of CA $\left(3.00 \mathrm{~g} / 6.00 \mathrm{~mL} \mathrm{H}_{2} \mathrm{O}\right)$ was added to an aqueous solution of CSA (4\% wt.) and stirred for about $10 \mathrm{~min}$. Different amounts of CA were added, ranging from 0.12 to $6 \mathrm{~mL}$, depending on the specific mass ratio of CSA/CA intended. In all cases, the total volume varied from 9 to $11 \mathrm{~mL}$, depending on the specific CSA/CA ratio used (Table S1 in the Supplementary Materials). The $\mathrm{pH}$ of the solution was checked before and after CA addition, and the resulting solution was carefully poured onto custom-made Teflon molds ( $5 \mathrm{~cm}$ inner diameter a rough surface due to use) and allowed to dry. After a drying period of 4-5 days during which the solution was left to evaporate in air, the resulting materials were collected and analyzed.

\subsection{Methods}

Fourier transformed infrared spectra obtained in attenuated total reflectance mode (ATR-FTIR) spectra were recorded with an IRaffinity1S Shimadzu spectrometer equipped with a horizontal unique reflection (a)

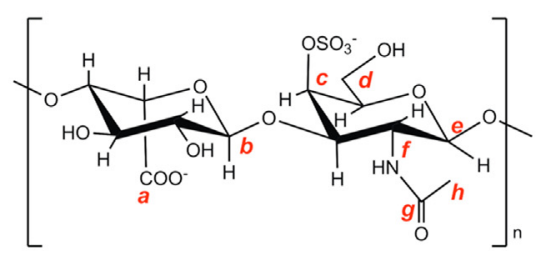

(b)<smiles>O=C(O)[C+]C(O)([18C]C(=O)O)C(=O)O</smiles>

(c)

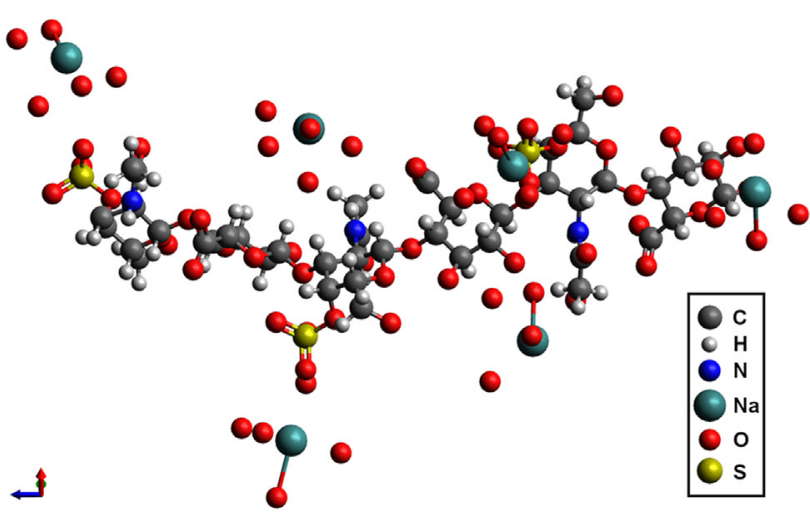

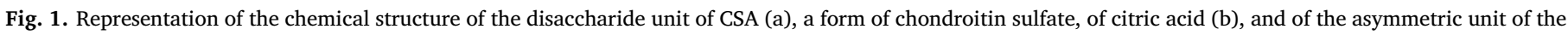
sodium salt of CSA (c), which was used in this work, as obtained from the data collected from [30]. 
ATR accessory (Golden Gate). The sample was placed over the diamond crystal with the help of a spatula. All spectra were obtained with 128 scans between 4000 and $400 \mathrm{~cm}^{-1}$ with a resolution of $2 \mathrm{~cm}^{-1}$.

The Differential Scanning Calorimetry (DSC) curves of the samples were recorded at a heating rate of $10{ }^{\circ} \mathrm{C} \mathrm{min}^{-1}$ under a flowing argon atmosphere. Each sample was placed in a $40 \mu \mathrm{L}$ perforated aluminum pan and the thermogram was recorded using a Mettler DSC 821e.

Thermogravimetric analyses (TGA) and additional DSC measurements were carried out in a DTA/TGA Netsch STA 449F3 thermal analyzer. In a typical experiment, samples were heated from room temperature to $700{ }^{\circ} \mathrm{C}$ in alumina $\left(\mathrm{Al}_{2} \mathrm{O}_{3}\right)$ crucibles under a nitrogen $\left(\mathrm{N}_{2}\right)$ atmosphere (50 $\mathrm{mL} \mathrm{min}{ }^{-1}$ purge; $20 \mathrm{~mL} \mathrm{~min}^{-1}$ protective flow), at a heating rate of $10{ }^{\circ} \mathrm{C} \mathrm{min}-1$.

Polarized Optical Microscopy (POM) images were recorded in an OPTIKA B-600 Pol microscope. The images were obtained through a digital camera 8 Mpixel Digital Photo and were analyzed with Optika Vision Pro software.

Solid state Nuclear Magnetic Resonance (NMR) experiments were conducted at CICECO - Aveiro Materials Institute, using a Spectrometer Bruker Avance III 400 wide-bore ( $400 \mathrm{MHz},{ }^{1} \mathrm{H}$ Larmor frequency). A $4 \mathrm{~mm}$ double-resonance Magic Angle Spinning (MAS) probe was employed at $100.6 \mathrm{MHz}\left({ }^{13} \mathrm{C}\right)$ Larmor frequency. Samples were spun in $\mathrm{ZrO}_{2}$ rotors using a spinning rate of $12 \mathrm{kHz} .{ }^{13} \mathrm{C}$ Cross Polarization (CP)/MAS NMR spectra were recorded using a ramp step (varying from 100 to $50 \%$ in amplitude using 100 points), with a recycle delay of $5 \mathrm{~s}$, a contact time of $2.0 \mathrm{~ms}$ and ${ }^{1} \mathrm{H} 90^{\circ}$ excitation pulse of $3.20 \mu \mathrm{s}$. All chemical shifts are quoted in parts per million (ppm) from tetramethylsilane (TMS).

$\mathrm{pH}$ measurements were obtained with a HANNA pH20 pH-meter at room temperature. All buffer solutions employed in the calibration of the $\mathrm{pH}$-meter were obtained from VWR Chemicals.

The ionic conductivity $(\sigma)$ of the samples was determined under real conditions by locating an electrolyte disk between two $10 \mathrm{~mm}$ diameter ion-blocking gold electrodes (Goodfellow, > 99.95\%) to form a symmetrical cell. The electrode/sample/electrode assembly was secured in a suitable constant volume support and installed in a Büchi TO51 tube oven with a K-type thermocouple placed close to the electrolyte disk to measure the sample temperature. Bulk conductivities of the samples were obtained during heating cycles by using the complex plane impedance technique with the Autolab PGSTAT-12 (Eco Chemie) equipment between room temperature and $110{ }^{\circ} \mathrm{C}$ and at approximately $15{ }^{\circ} \mathrm{C}$ intervals. The ambient relative humidity (RH) was lower than $30 \%$.

The ionic conductivity of membranes was also determined at room temperature $\left(\sim 26^{\circ} \mathrm{C}\right)$ and under variable $\mathrm{RH}(30-98 \%)$ by impedance spectroscopy using an Agilent E4980A Precision LCR meter. The through-plane (TP) configuration was adopted and the membranes were placed between two carbon cloth gas diffusion layers $\left(\sim 0.5 \mathrm{~cm}^{2}\right)$ and graphite plates with gas channels. The samples were mounted on an appropriate support and placed in a climatic chamber made in-house, where variable relative humidity $(\mathrm{RH})$ conditions were achieved using different saturated salts solutions. The RH was constantly monitored close to the sample with a humidity sensor. The impedance spectra were collected between $20 \mathrm{~Hz}$ and $2 \mathrm{MHz}$ with a test signal amplitude of $100 \mathrm{mV}$. Spectra were analyzed with ZView (Version 2.6b, Scribner Associates) to assess the ohmic resistance (R), which was normalized to the samples geometry to calculate the conductivity through the usual formula $\sigma=L(R A)^{-1}$, where $L$ is the distance between the in-plane silver stripes (or the thickness of the membranes) and $A$ is the crosssection area of the membranes (or the surface area of the electrodes).

The Atomic Force Microscopy (AFM) analysis was performed in an AFM CSI Nano-Observer equipment (Scientec) in tapping mode using a super sharp Si HQ:NSC19/FORTA probe with a frequency resonance of $60 \mathrm{kHz}$ and a spring constant of $0.3 \mathrm{~N} \mathrm{~m}^{-1}$. In order to improve the quality of the images, flattening and elimination of line noise tools were applied using the Gwyddion 2.52 software. Because the samples produced were dried in air, the surface of the film was exposed to $\mathrm{N}_{2}$ prior to AFM analysis to clean any dust and fibers that might have been trapped due to air exposure. As the film was rather sticky, additional precautions were undertaken to avoid the insertion of indentations or film stretching. The film was deposited on double tape glue that was previously homogenized on the support to avoid the formation of bubbles. The AFM analysis was performed on the surface which had been exposed to air during the drying process. Indeed, due to the nature of the film itself, the surface in contact with the mold mimicked its patterns (e.g., scratches caused by prolonged use, including removal of films with spatula) (Fig. S1 in the Supplementary Material). Therefore it was decided that the analysis of the surface exposed to air would provide a deeper knowledge of the topographical characteristics of the film, regardless of the mold used.

Scanning Electron Microscopy (SEM) images of the top (exposed to air during drying) and bottom (in contact with the Teflon mold) surfaces, as well as the cross-section, of the samples were obtained at $20 \mathrm{kV}$ on a Hitachi S-3400 N type II microscope (Hitachi, Chiyoda, Japan) equipped with a Bruker x-flash 5010 at high vacuum. For the crosssection analyses, the cut was made at cryo-temperatures. All the samples were coated with gold in a rotating holder to ensure homogeneous distribution. Elemental mapping of the samples was performed by Energy Dispersive Spectroscopy (EDS) X-ray analysis. The acceleration voltage and intensity of the beam current were chosen taking into consideration the chemical composition of the samples. In addition, both parameters were optimized to maximize high count and low deadtime. The acquisition time for a satisfactory resolution and noise performance was $60 \mathrm{~s}$. As the films were flat, the directionality was neglected in the measurements.

\section{Results and discussion}

CSs are low charge density structures which include several functional groups prone to protonation (Fig. 1a): most notably an amide group, a carboxylic group and a sulfonic group, but also an ether and hydroxyl groups, meaning that the same structure features both weak and strong acidic groups [32,37]. In our working conditions, the measured $\mathrm{pH}$ of a $4 \%$ aqueous solution of CSA was 6.0 , indicating that both the weakly acidic carboxylic group (pKa 3.5-4.6) and the strongly acidic sulfonic group (pKa 2.6) were deprotonated [32,52].

The addition of a concentrated CA solution to the CSA aqueous solution led to an immediate drop in $\mathrm{pH}$, and the concomitant appearance of some turbidity. However, this turbidity ultimately disappeared (Table 1 and S1 in the Supplementary Material). Different combinations of mass ratios of CSA and CA, henceforth designated by $\mathrm{CA}: \operatorname{CSA}(\mathrm{X})$ where $\mathrm{X}$ indicates the specific mass ratio used, afforded different end products, from powders to films (Table 1).

Table 1

Relevant data of the synthesis of the CA:CSA(X) electrolytes.

\begin{tabular}{llll}
\hline $\mathrm{X}(\%)$ & $\mathrm{pH}$ & Product & $\mathrm{H}_{2} \mathrm{O}$ content $(\mathrm{wt} / \mathrm{wt} \%)^{*}$ \\
\hline 0 & 6.03 & brittle film & 11.41 \\
15.2 & 3.55 & brittle film & 9.53 \\
29.2 & 3.12 & & 10.01 \\
43.6 & 2.89 & flexible film & 9.53 \\
60.8 & 2.55 & & 7.11 \\
75.6 & 2.21 & flexible, sticky film & 6.67 \\
82.3 & 2.07 & & 7.43 \\
83.4 & 2.00 & Polycrystalline powders & 6.91 \\
84.4 & 1.95 & & 7.48 \\
86.1 & 1.88 & & 4.54 \\
90.3 & 1.73 & & 6.18 \\
92.5 & 1.66 & & 6.77 \\
93.7 & 1.62 & & 7.86 \\
100 & 1.42 & & \\
\hline
\end{tabular}

* As measured by TGA. 
Films were obtained for a wide range of $\mathrm{X}$ values, ranging from 15.2 to $82.3 \%$, from solutions with $\mathrm{pH}$ values as low as $\sim 2.1$ (Table 1 and Fig. S2 in the Supplementary Material). These films exhibited different properties, depending on CA concentration. Thus, low concentrations of CA ( $\mathrm{X}<43.6$ and $\mathrm{pH}>3.0$ ) afforded brittle films, probably due to the insufficient protonation of CSA by CA $\left(\mathrm{pKa}_{1}=3.13, \mathrm{pKa}_{2}=4.76\right.$ and $\left.\mathrm{pKa}_{3}=6.40\right)$ [53]. For $43.6<\mathrm{X}<70.1(2.55<\mathrm{pH}<2.89)$ non sticky films were produced. Sticky flexible films were obtained for $70.1<\mathrm{X}<82.3(2.07<\mathrm{pH}<2.29)$. These results point out a trend between the flexibility of the film and the increasing amount of CA, as a result of the formation of new intermolecular hydrogen bonds which occurs at the expense of the existing intramolecular interactions of CSA [54]. Moreover, this trend confirms the CA role as a plasticizer in the formation of SPEs $[46,47]$.

The incorporation of higher amounts of $\mathrm{CA}(\mathrm{X}>83.4 \%, \mathrm{pH} \leq 2.0)$ led to the gradual precipitation of a white powder. Given the observed $\mathrm{pH}$ of the parent solution, a strong interaction between the CA and the anionic polysaccharide was expected, in a similar manner as reported for other SPEs obtained with CSA at low pH [55].

\subsection{Spectroscopic characterization of the CA:CSA electrolytes}

\subsection{1. ${ }^{13} \mathrm{C}$ CP-MAS NMR spectroscopy}

${ }^{13} \mathrm{C}$ NMR spectroscopy is known to provide relevant information about the structure of CSA and related polysaccharides, such as the pattern of sulfation, conformation of the polysaccharide or even hydrogen bonding $[56,57]$. The ${ }^{13} \mathrm{C}$ CP-MAS NMR data collected for both the starting materials are presented and discussed in the Supplementary material.

The ${ }^{13} \mathrm{C}$ CP/MAS NMR spectra of the CA:CSA electrolytes exhibit signals pertaining to both CSA and CA (Fig. 2 and Fig. S4 and Table S2, Supplementary Material). At $\mathrm{X}=60.8$ the ${ }^{13} \mathrm{C} \mathrm{CP} / \mathrm{MAS}$ NMR spectrum is still dominated by the CSA resonances. However, the carboxyl resonance, centered at $176.0 \mathrm{ppm}$, appears as a broad, asymmetric signal, with new shoulders at 179.4 and $173.6 \mathrm{ppm}$ due to the carboxylic groups present in the CA moiety (Fig. 2). A new broad signal located at 43.7 ppm emerges, due to the CA methylene carbons (Fig. S3). As higher amounts of CA are progressively added to the CSA biopolymer, several changes occur until the spectra are entirely dominated by the characteristic resonances of $C A$ (at $X \geq 82.3$ ). The sharpening of the signals seen for $X \geq 82.3$, indicate the high structural order of the

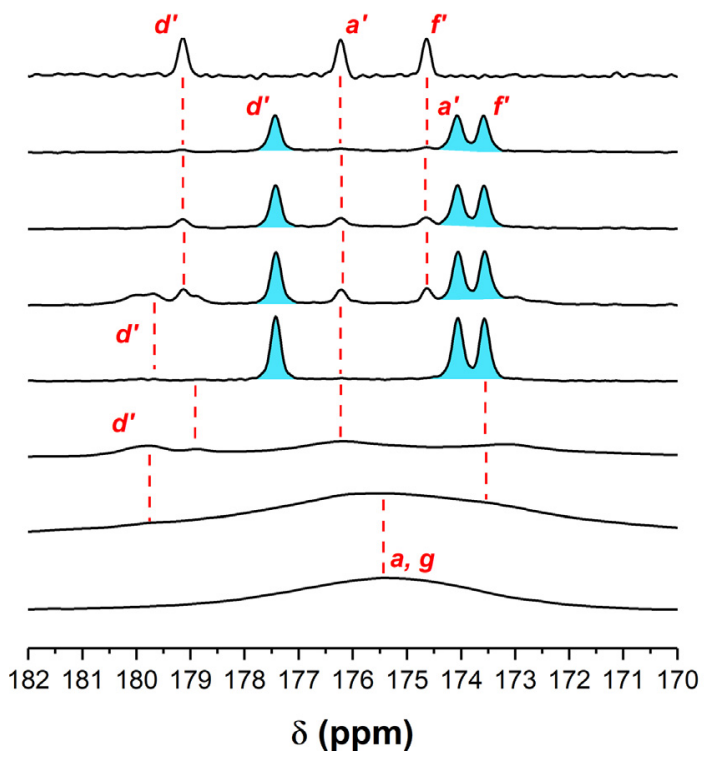

X 100

86.1

84.4

83.4

82.3

75.6

60.8

0

Fig. 2. ${ }^{13} \mathrm{C}$ CP-MAS NMR expansion for the carbonyl carbon groups of CSA, CA and the various electrolytes prepared. Blue shaded peaks are due to CA monohydrate. powdered material, in contrast with the broad signals produced by films (for $\mathrm{X}<82.3$ )

Two different regions are of particular interest: the region between 182 and 170 ppm (Fig. 2), corresponding to the carbonyl groups, and the region between 110 and $90 \mathrm{ppm}$, related to the glycosidic bonding (Fig. S4).

In the carbonyl region $(182<\mathrm{ppm}<170)$, the CSA signal at $176 \mathrm{ppm}$ is visible up to $\mathrm{X}=60.8 \%$, with higher amounts of added CA leading to spectra dominated by the resonances of the CA carboxylic groups (Fig. 2). In the spectra of CA:CSA electrolytes with $82.3 \leq \mathrm{X}<100$, three prominent resonances are observed at 177.4, 174.1 and $173.6 \mathrm{ppm}$, which do not coincide with the characteristic resonances of the CA precursor, observed at 179.4, 176.0 and 174.6 ppm (Fig. 2). Fisher et al. associated those resonances with CA monohydrate [58]. In addition, weak signals at 179.2, 176.2 and $174.6 \mathrm{ppm}$ are seen in some spectra, indicating the presence of a secondary phase consisting of anhydrous $\mathrm{CA}$, as suggested by the spectrum of the pure precursor and by the literature data [58]. As the ${ }^{13} \mathrm{C} \mathrm{CP}$ / MAS NMR spectra for the CA:CSA electrolytes with $\mathrm{X}>82.3$ are dominated by the resonances of CA in its various forms, we can conclude that for these particular formulations, there is an excess of CA present in the collected powders. In $\mathrm{X}>82.3$, the predominance of the CA monohydrate signals over the CA anhydrous signals strongly suggests that the powders here obtained are mostly constituted by CA monohydrate with a secondary phase consisting of CA:CSA(X) electrolytes, which could be justified by the considerable CA molecular aggregation arising from the hydrogen bonding interaction between both CA and water [59].

Over the whole $X$ range investigated, no signals above $180 \mathrm{ppm}$ were detected. The absence of these signals, which are related with the formation of sodium citrate [58], indicates that the sodium counter-ions present in the raw CSA sample did not complex with CA.

In the region between 110 and $90 \mathrm{ppm}$ (Fig. S4), the broad signal observed at $102.8 \mathrm{ppm}$, for CSA, gradually shifted into a duplet at $\mathrm{X}=75.6$, as a consequence of a change in the chemical environment of the glycosidic bridge $[60,61]$. According to previous works [60-62], two resonances are expected in this region of the CSA ${ }^{13} \mathrm{C}$ NMR spectrum, respectively at 106.5-105 and 103.5-102 ppm, due to the (1-4)$\beta$-linked C-1 carbon (peak $b$ ) and (1-3)- $\beta$-linked C-1 carbon (peak $e$ ), respectively. In this work, the same resonances appear at 104.2 and $101.2 \mathrm{ppm}$. The envelope that contains both signals remains centered in the same area as the starting CSA material (Fig. S3 and Table S2). Hamer et al. observed no significant shift of these signals when CSA was acidified to a $\mathrm{pH} \sim 1$. [60]. In a study involving the interaction between chondroitin sulfate- 6 (CSC) and chitosan, the authors observed a shift of the resonance associated with the anomeric carbon from 104.7 to $99.3 \mathrm{ppm}$, which was attributed to the electrostatic interactions between both electrolytes [38]. Given that the difference between CSC and the CSA used in this work is simply the location of the sulfonic group (which in our case is located at the C4 position of the $\mathrm{N}$-acetylgalactosamide ring, instead of the $\mathrm{C} 6$ position of the same ring), this might have led to a smaller upfield shift than that observed by Chen et al. [38], since the presence of sulfonic groups in neighboring atoms is known to induce higher chemical shifts [57].

From the gathered evidence, we deduce the nature of the interaction between CSA and CA is probably electrostatic, as observed for other materials containing CSA $[37,38,63,64]$, especially at low $\mathrm{pH}(\leq 2)$. It has been argued that at low $\mathrm{pH}$, a competition exists between the protonation of the polyanionic sites of CSA and their complexation with the $\mathrm{Na}^{+}$cations $[37,38]$, which might result in the condensation of the acidic and sodium cations around the CSA backbone $[65,66]$.

\subsubsection{ATR-FTIR spectroscopy}

The ATR-FTIR spectra of the CA:CSA electrolytes, and of pure CSA and CA are reproduced in Figs. 3 and S5 (in the Supplementary Material). Relevant ATR-FTIR data are collected in Table S3. Of 


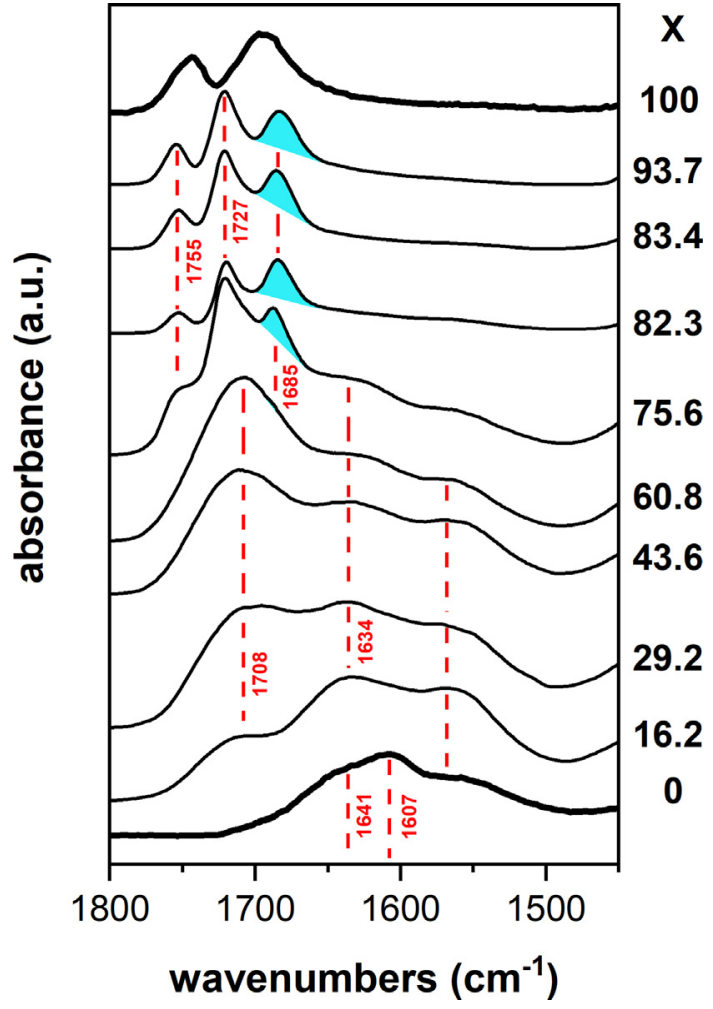

Fig. 3. ATR-FTIR spectra of CSA, CA and selected CA:CSA(X) electrolytes in the 1800-1450 $\mathrm{cm}^{-1}$ region. Blue shaded bands indicate the presence of CA monohydrate.

particular interest is the spectral interval of $1800-600 \mathrm{~cm}^{-1}$, found to be the most useful for the identification of the vibrational modes of CSA and CA $[67,68]$.

The analysis of these ATR-FTIR spectra is complicated by the fact that vibrational modes of different origins appear superimposed in most of the spectral regions.

In the spectrum of CSA, the asymmetric stretching vibration of the carboxylate groups $\left(\mathrm{\nu}_{\mathrm{as}} \mathrm{COO}^{-}\right)$emerges as a very strong band centered at $1607 \mathrm{~cm}^{-1}$ with two shoulders at 1641 and $1551 \mathrm{~cm}^{-1}$ (Fig. 3), due to the Amide I and Amide II vibrations, respectively [68-72]. According to the literature, the shift of the CSA band at $1611 \mathrm{~cm}^{-1}$ to lower wavelengths $\left(1607 \mathrm{~cm}^{-1}\right)$ is indicative of the presence of hydration waters, interacting with the carboxylate groups through hydrogen bonds [72].

The asymmetric stretching vibration of the carboxylic groups $\left(v_{\mathrm{as}} \mathrm{COOH}\right)$ in CSA is expected between 1740 and $1720 \mathrm{~cm}^{-1}$ $[37,69,71]$. In the ATR-FTIR spectrum of CA the $\nu_{\text {as }} \mathrm{COOH}$ mode is observed at 1743 and $1693 \mathrm{~cm}^{-1}$ (Fig. 3). These bands are assigned to the central carboxylic group and to the terminal carboxylic groups, respectively [73-75].

When CSA and CA are combined, changes in the shape, number and wavenumber of the carboxylate bands can be seen in this particular region of the spectra, indicating strong interactions between both starting materials. As expected, as the amount of CA added to the CSA solution increased, the maximum of the band envelope due to the asymmetric stretching vibration of the carboxylate groups, $\nu_{\mathrm{as}} \mathrm{COO}^{-}$, mode of the polymeric moiety gradually shifted to higher wavenumbers, first with a band centered at $1708 \mathrm{~cm}^{-1}$ (for $\mathrm{X} \leq 60.8$ ) and then with a band located at $\sim 1727 \mathrm{~cm}^{-1}$ (for $X \geq 75.6$ ) (Fig. 3). This shift, along with the disappearance of the $\nu_{\mathrm{as}} \mathrm{COO}^{-}$band at $1607 \mathrm{~cm}^{-1}$, is indicative of the gradual protonation of the electrolyte. At $X \geq 75.6$, two new bands are clearly seen at 1755 and $\sim 1685 \mathrm{~cm}^{-1}$ (Fig. 3). The band located at $1685 \mathrm{~cm}^{-1}$ is attributed to the CA monohydrate [74].
The band at $1755 \mathrm{~cm}^{-1}$ is due to the presence of the dimeric form of CA $[44,75]$, probably due to the establishment of hydrogen bonds between the carboxylic groups of each monomer $[44,75]$. The presence of this particular form of CA is the only to be expected, given the low working $\mathrm{pH}$ (which favors hydrogen bonding) and is in agreement with the ${ }^{13} \mathrm{C}$ CP/MAS NMR data.

The symmetric stretching vibration of the carboxylate groups $\left(\nu_{\mathrm{s}} \mathrm{COO}^{-}\right.$) [68-70,72-75] is located at $1408 \mathrm{~cm}^{-1}$ in CSA, $1416 \mathrm{~cm}^{-1}$ in CA, and 1416-1419 $\mathrm{cm}^{-1}$ in the prepared CA:CSA adducts (Fig. S5, Supplementary Material). No relevant changes were detected as a function of $\mathrm{X}$.

Sulfonic characteristic modes [68-70,72] are found at $1224 \mathrm{~cm}^{-1}$ (with a shoulder at $1261 \mathrm{~cm}^{-1}$ ), associated with the asymmetric stretching vibration of the sulfate groups $\nu_{\text {as }}\left(\mathrm{OSO}_{3}{ }^{-}\right)$mode, and at 851 and $720 \mathrm{~cm}^{-1}$, due to the asymmetric stretching vibration of the carbon-sulfate bond, $\nu_{\text {as }}(\mathrm{C}-\mathrm{O}-\mathrm{S})$ (Fig. S4). While the bands derived from the CSA carbon backbone remain unchanged in all the CA:CSA samples prepared, a shift of $-18 \mathrm{~cm}^{-1}$ (from 1224 to $1206 \mathrm{~cm}^{-1}$ ) was observed (Fig. S5) in the $\nu_{\text {as }}\left(\mathrm{OSO}_{3}{ }^{-}\right)$band as the amount of CA increased. Servaty et al. argued that the occurrence of the shoulder located at $1261 \mathrm{~cm}^{-1}$ might be due to non-symmetric water-mediated interactions between the $\mathrm{Na}^{+}$counterions and the sulfonic group [72]. As increasing amounts of CA were added to the CSA solution, the overall $\mathrm{pH}$ of the solution decreased. The $\mathrm{pH}$ thus approached the $\mathrm{pKa}$ for $-\mathrm{OSO}_{3} \mathrm{H}$ (about 2.6), $\left[-\mathrm{OSO}_{3} \mathrm{H}\right] \approx\left[-\mathrm{OSO}_{3}{ }^{-}\right]$and changes in the local chemical environment around the sulfonic groups occurred.

\subsection{Morphological studies of the prepared electrolytes}

As reported earlier, the combination of CSA and CA led to the formation of powders and films, depending on the value of $\mathrm{X}$. Given that these two series of materials have very different properties, the discussion that follows henceforth will be focused exclusively on the films. The results obtained for the powders are reported in the supplementary material. Films were formed at room temperature in a period of 4-5 days, following the addition of a concentrated CA solution to a $4 \%$ aqueous CSA solution. These translucent films were produced for all combinations of CSA and CA where X $<82.3 \%$ (Table 1).

The POM images confirm that CSA is practically amorphous (Fig. 4A and $\mathrm{B}$ ). However, when $\mathrm{CA}$ was added to the solution, isolated birefringent entities emerged in all the films, indicating the presence of crystalline regions (Fig. 4C-H).

The SEM images of the top and bottom surfaces, as well as the cross section of films with $X<60.8$ are represented in Fig. 5. The smoothest surfaces were obtained for the CA:CSA(X) samples with $\mathrm{X}=60.8$ (Fig. 5D) and 43.6 (Fig. 5D). At higher $X$, the surfaces became more irregular, culminating with clearly visible cracks in $\mathrm{X}=82.3$ (Fig. S6 in the Supplementary Material).

The corresponding EDSs mapping images for CA:CSA(X) films with $X=43.6$ and 60.8 are shown in Fig. 6 . The distribution maps for the more concentrated films can be seen in Fig. S7 in the Supplementary Materials. The obtained profiles for the distribution of $\mathrm{S}$ and $\mathrm{N}$ atoms (present only in CSA) demonstrate that the polymer is homogeneously distributed in the analyzed area. Moreover, for these films, the profile for the $\mathrm{Na}^{+}$cations matches that seen for the sulfonic group, suggesting that for CA-poor films where $\mathrm{X} \leq 60.8$, the sulfonic groups are bound to the $\mathrm{Na}^{+}$cations.

The full scale view of the film placed on the AFM analysis support shows that the sample CSA/CA(60.8) is homogenous (Fig. 7E) and the film topographical analysis revealed a medium roughness of $2.99 \mathrm{~nm}$, which is consistent with the film macroscopic appearance. A close analysis revealed pore-like structures of different sizes and with a medium depth of $50 \mathrm{~nm}$ throughout the film (Fig. 7A-D). Moreover, it is also possible to see non-uniform structures (bright angular structures on the topographical images) that seem to have developed as the film dried out, since they are in different planes. These structures did not 

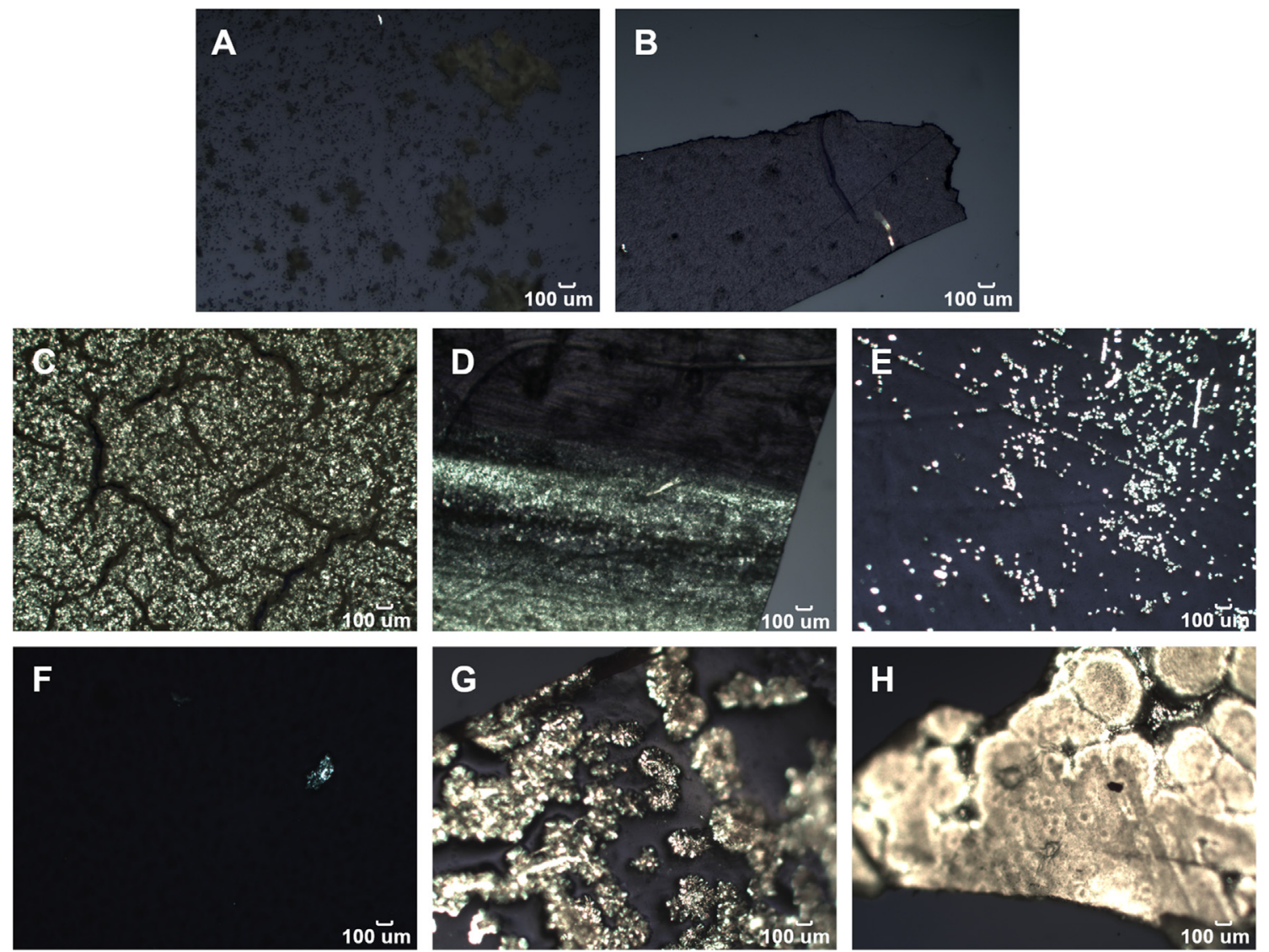

Fig. 4. POM images obtained with crossed polarizers for CSA as received (A); CSA film (B); and CA:CSA(X) electrolytes with X = 15.2 (C); 29.2 (D); 43.6 (E); 60.8 (F); $75.6(\mathrm{G})$ and $82.3(\mathrm{H})$.

suffer any detectable morphology alteration by the action of the cantilever passage and their size range from 0.88 to $2.60 \mu \mathrm{m}$ in length. Taking into consideration the film formation and the characteristics showed by the AFM analysis, it is quite possible that these angular structures are indeed crystallites formed during the solvent evaporation process, as previously described by [59].

\subsection{Thermal stability}

According to the TGA data (Figs. 8 and S9 in Supplementary Material), thermal decomposition of all the CA:CSA(X) electrolytes with $\mathrm{X} \leq 82.3$ invariably occurs in two steps: (1) loss of water below $120{ }^{\circ} \mathrm{C}$ (5-10\% weight loss) and (2) major thermal degradation with onset at $120-140{ }^{\circ} \mathrm{C}$.

As the $\mathrm{pH}$ decreases, the strength of the electrostatic interaction first increases, and then, at very low $\mathrm{pH}$ values, decreases due to the increment of the repulsion of the protonated groups. A decrease in the water content of the solids is an indication of a more compact CSA conformation $[63,76,77,78]$, which is prone to increase any repulsion effect on the protonated groups. On the other hand, Volpi et al. pointed out that the presence of acidic compounds, such as the CA used in this work, leads to an acid-catalyzed hydrolysis of the glycosidic linkages at moderate temperatures [79]. Such a mechanism might help explain what is happening here. Moreover, the comparison of the degradation onset values of the CA:CSA(X) compounds with those found for DESs obtained from combinations of simple sugars and organic acids [26,28], further suggests a thermal decomposition mechanism affecting primarily the CSA structure, as no gain in thermal stability was observed when a simple sugar is replaced by a polysaccharide, such as CSA.

\subsection{Ionic conductivity}

The Arrhenius conductivity plot of CA:CSA(X) electrolytes with $X=43.6,60.8$ and 82.3, shown in Figs. 9A and S10 (in Supplementary Material), for data, demonstrates that at room temperature CA:CSA(43.6) has a lower ionic than the polysaccharide precursor, whereas the remaining two films tested $(X=60.8$ and 82.3) feature a proton conductivity higher than CSA. These results, along with those observed for the powdered samples (Fig. S14 in Supplementary Material), indicate that the proton conductivity enhancement effect due to the presence of CA is only observable in a limited range of X. Low and high $\mathrm{X}$ values give rise to electrolytes with poorer ionic conductivity.

The effect of composition can be rationalised admitting chemical interaction between the mixture components. Indeed, CA is expected to interact with the anionic groups present in CSA.

As the CA molecule possesses two terminal carboxylic groups, the interaction probably occurs through cross-linking between the carboxylic groups of CA and the anionic groups present in the polysaccharide (carboxylate and sulfate groups, for low and high CA content, respectively) (Fig. S11, in Supplementary Material). Similar reaction schemes have been proposed for electrolyte systems formed between chitosan and organic acids $[47-49,80]$. The addition of CA to the CSA allows the formation of intermolecular interactions between CSA and CA at the expense of the existing intermolecular interactions between the amide and the carboxylic groups of the polysaccharide, resulting in the enlargement of the distance between the CSA chains with the increase of CA content and in an increase of the tensile strength of the electrolyte [47].

The ionic conductivity data can be explained in terms of the content of CA present in the electrolytes.

As indicated in Section 3.1, a freshly prepared solution of CSA had a 


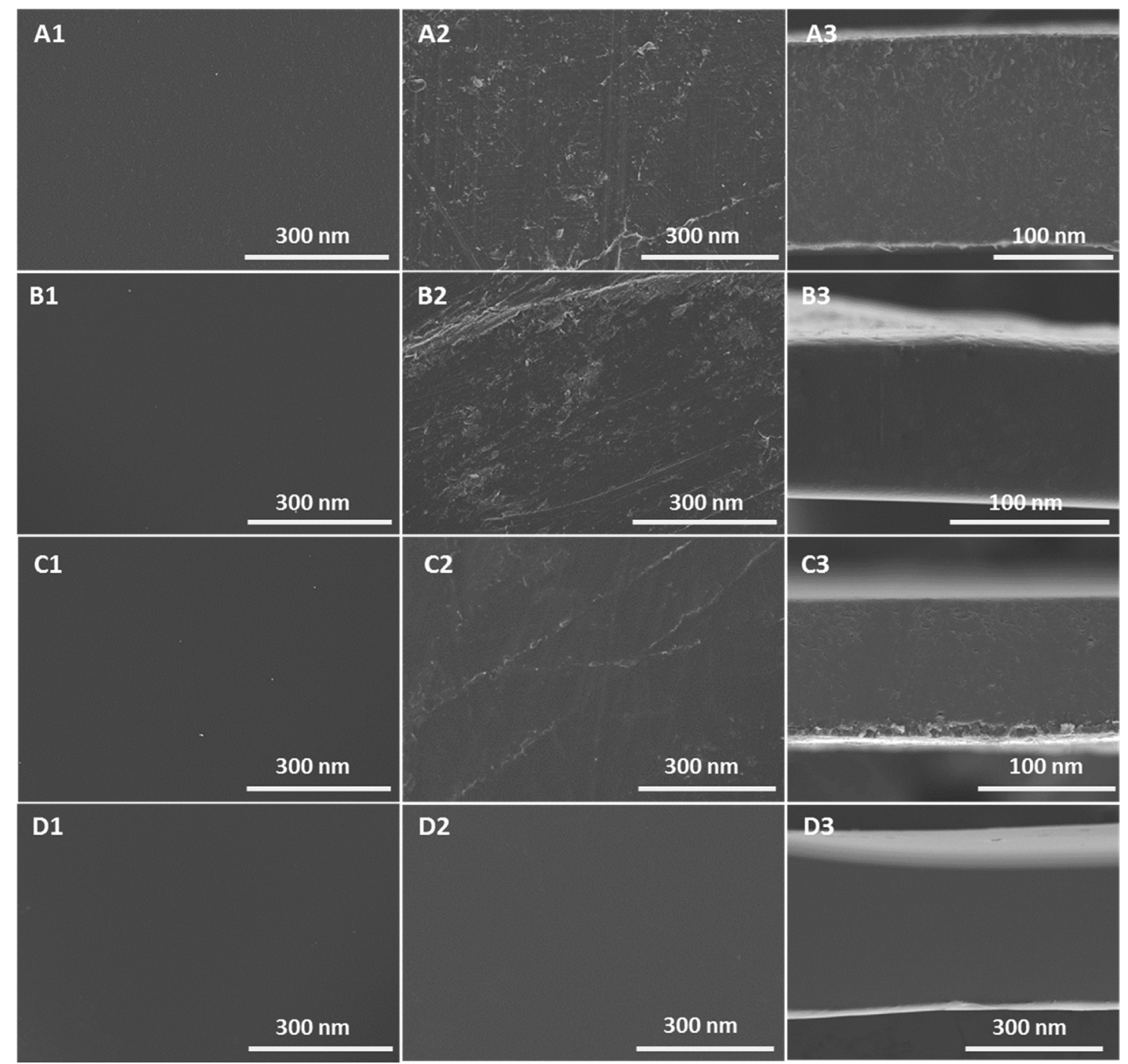

Fig. 5. SEM images of the top (1) and bottom (2) surface, and cryogenic temperature cross-section (3) of the CA:CSA(X) films, with X = (A) 15.2; (B) 29.2; (C) 43.6; and (D) 60.8 .

$\mathrm{pH}$ of 6.0. The addition of CA leads to a decrease of the $\mathrm{pH}$, and thus should lead to an increase of ionic conductivity. However, with CA acting as a cross-linker (Fig. S11), the low content of CA might not be enough to improve on the mechanical properties of the CSA films. The lower ionic conductivity values observed for CA:CSA(43.6) can thus be attributed to a low content of CA, which leads to the formation of films with poor mechanical properties and low intermolecular interactions between CSA and CA $[47,65,66]$. In the same way, the enhancement in ionic conductivity observed for CA:CSA(X) electrolytes with $\mathrm{X}=60.8$ and 82.3 can be explained with the higher amount of CA which led to
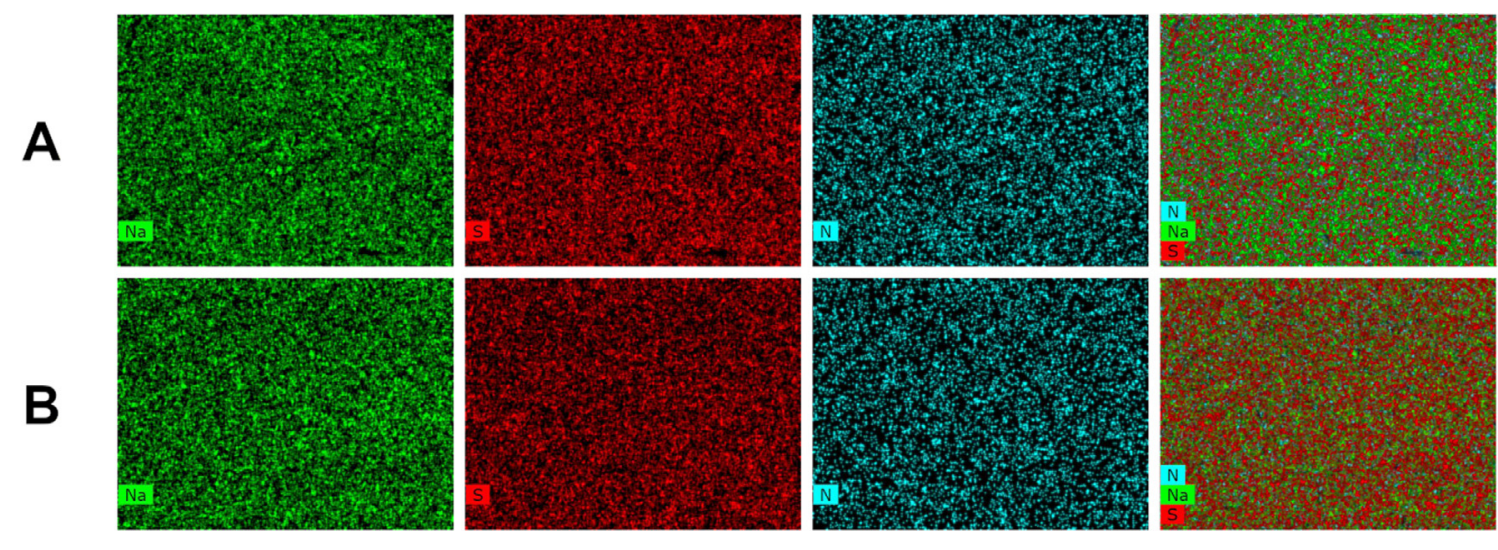

Fig. 6. EDS mapping images for the top surfaces of the CA:CSA(X) films, with $X=43.6$ (A); 60.8 (B) for the elements Na (green), $S$ (red) and $N$ (cyan). The last column is a composite image obtained from the juxtaposition of all three elements. 

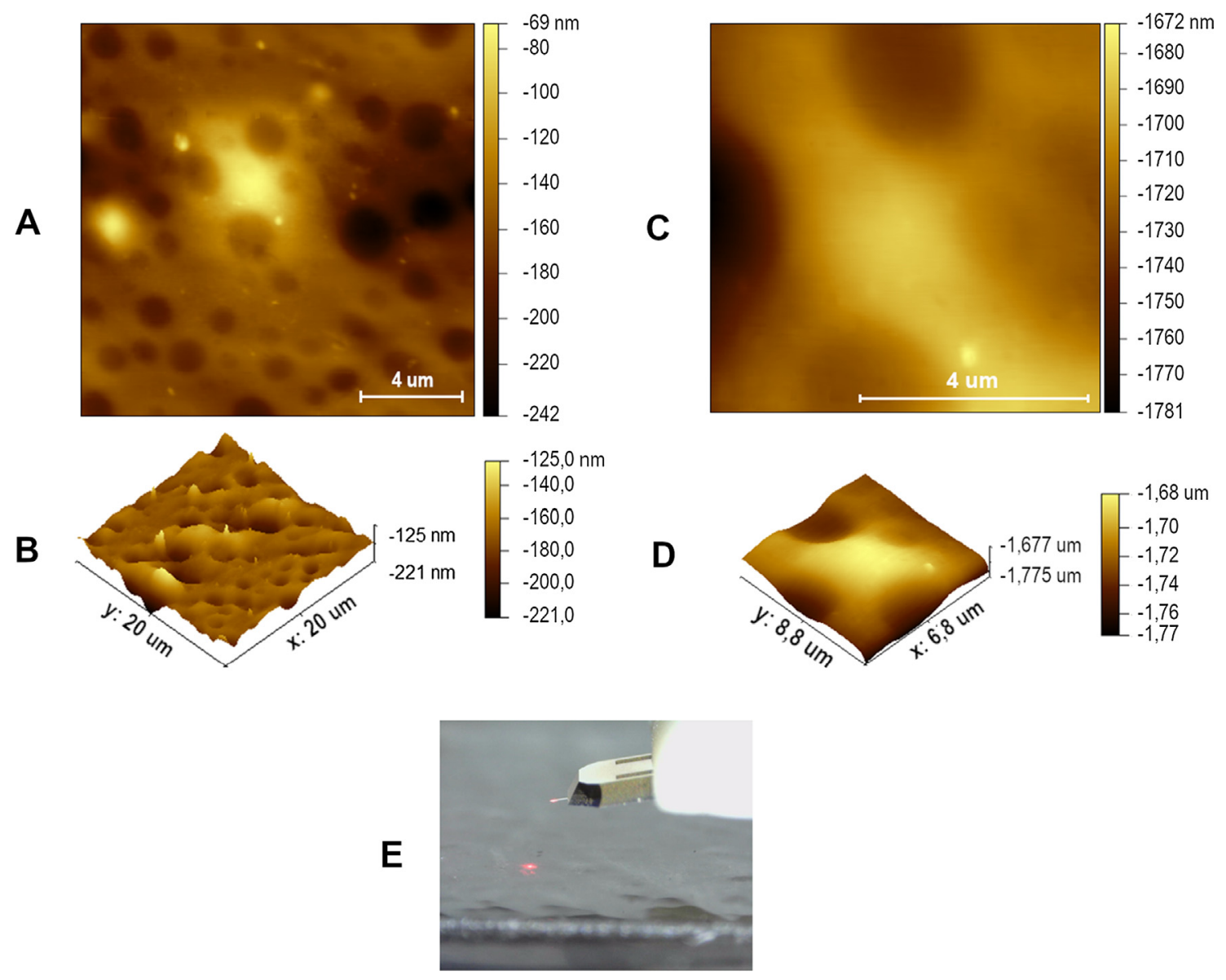

Fig. 7. AFM characterization of the CA:CSA(60.8) film: (A,C), 2D topographical and (B,D) 3D topographical images of $20 \mu \mathrm{m}$ and $6.8 \mu \mathrm{m}$, respectively, obtained in resonant mode. (E) Image acquired on the AFM support prior to performing the analysis.

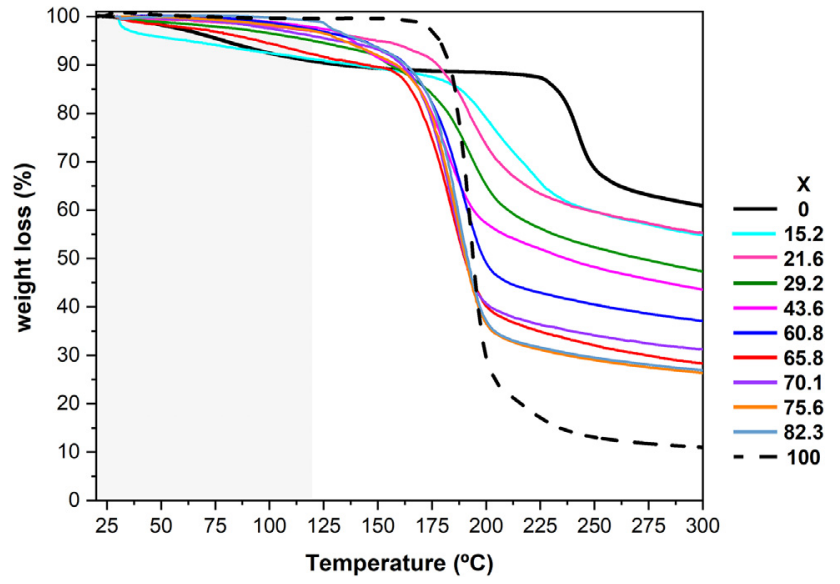

Fig. 8. TGA curves for CA, CSA and CA:CSA(X) electrolytes with $X<83.4$ in the $30-300{ }^{\circ} \mathrm{C}$ range.

more compact and stronger films. CA:CSA(60.8), which yields the highest proton conductivity at room temperature, has been found to be one of the most homogenous films prepared out of the whole series here described, with the spectroscopic data indicating no clear excess of either CSA or CA. On the other hand, CA:CSA(82.3) has been shown to possess both an excess of CA, as indicated in Section 3.2., and a remarkably different morphology than that observed for the remaining electrolytes of this series. This particular sample, which seems to be at the transition between the formation of the film and the powders formed at higher CA content, still possesses enough amorphous content, as observed by POM measurements, which is believed to be responsible for the proton conductivity.

The temperature dependence of the ionic conductivity is irregular (Fig. S10 in Supplementary Material). The ionic conductivity increases for temperatures up to $50{ }^{\circ} \mathrm{C}$, which coincides with the CSA gel-sol transition (Fig. S8 in Supplementary Material). Above this transition temperature, the ionic conductivities decrease, probably due to the loss of mechanical properties. In addition, the CA:CSA(82.3) sample exhibits the highest proton conductivity at $50{ }^{\circ} \mathrm{C}$.

The conductivity values measured at room temperature and under variable relative humidity $(\mathrm{RH})$ are plotted in Fig. 9B. The proton conductivity of the membranes is highly humidity-dependent, with values ranging from $1.4 \times 10^{-7} \mathrm{~S} \mathrm{~cm}^{-1}$ for CA:CSA(82.3) at $30 \% \mathrm{RH}$ to $3.7 \times 10^{-2} \mathrm{~S} \mathrm{~cm}^{-1}$ for $\mathrm{CA} \operatorname{CSA}(60.8)$ at $98 \% \mathrm{RH}$, confirming that these membranes are highly hydrophilic. As expected, and in accordance with the results regarding the effect of temperature (Fig. S10 in Supplementary Material), the electrolyte with the lowest CA content $(X=43.6)$ shows the lowest proton conductivity values for $\mathrm{RH}$ higher than $30 \%$. At $98 \% \mathrm{RH}$ the conductivity of CA:CSA(43.6) reaches $2.1 \times 10^{-4} \mathrm{~S} \mathrm{~cm}^{-1}$, which is one order of magnitude lower than that measured for CSA. At RH higher than 50\% the CA:CSA(60.8) film presents the highest proton conductivity. One would expect higher proton conductivities for CA:CSA(82.3), since according to EDS data all the sulfonic groups at the surface are protonated. However, both the spectroscopic and the morphologic data point to the presence of a secondary phase consisting of pure CA. The lower values here observed, which are also in accordance with the ones seen in Fig. 9A and S10, are consistent with the occurrence of secondary processes such as the CA dimerization observed in Section 3.2, and of a lower intermolecular 

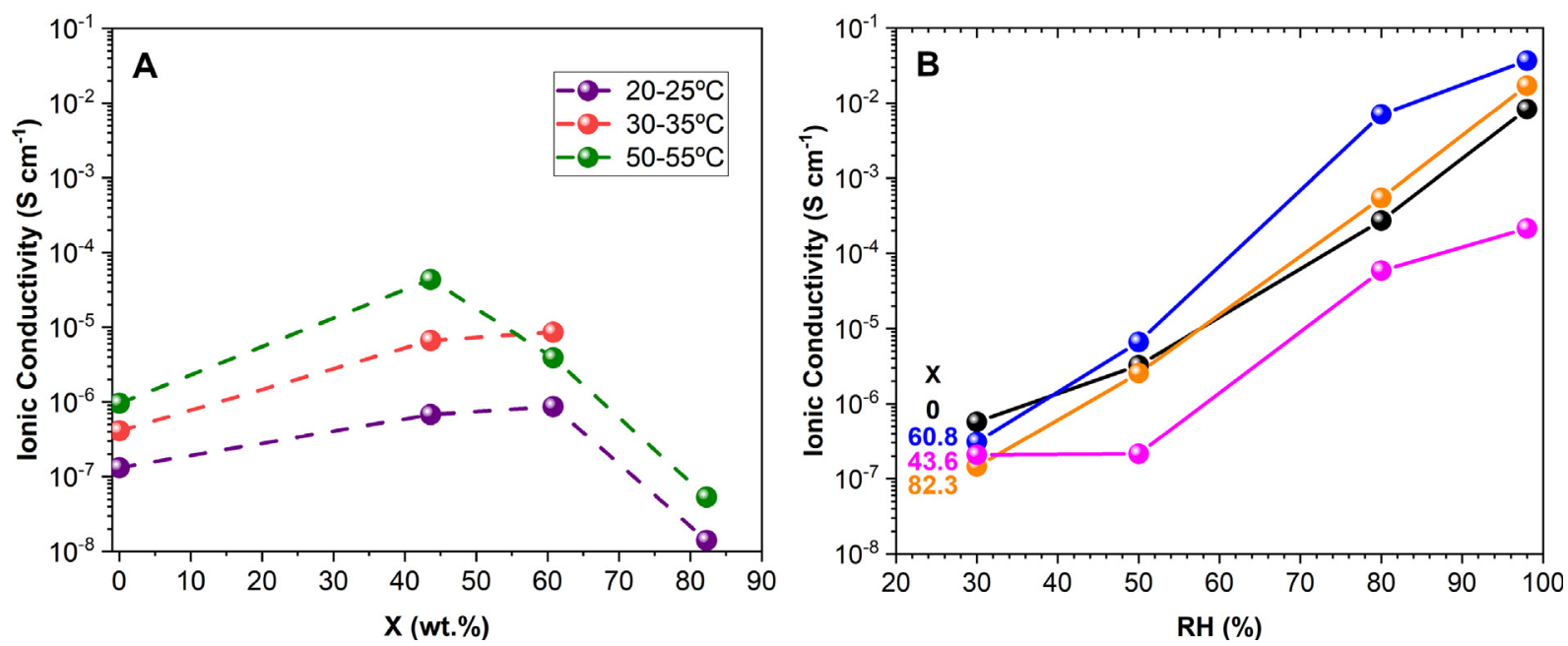

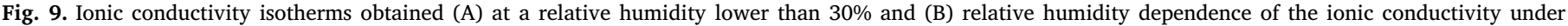
different $\mathrm{RH}$ at $25{ }^{\circ} \mathrm{C}$ for CSA and CA:CSA(X), with $\mathrm{X}=0,43.6,60.8$ and 82.3.

interaction between the CA and CSA than the one observed for CA:CSA(60.8).

The higher conductivity of CA:CSA(60.8) may be probably related to the formation of a system with an amorphous structure and improved dimensional stability (crack-free), that contributes to the overall increase of proton mobility [47]. Such apparent inconsistency may also result from the viscous deformation of the membranes at high humidity, leading to uncontrolled changes of the geometric factor (e.g. the decrease of membrane thickness) used to estimate the conductivity. In fact, after the measurements at $98 \% \mathrm{RH}$ the samples were found in a gel-like film, a fact that confirms the hydrophilic character of the materials and is a strong evidence that changes of the sample geometry may indeed occur during the measurements. These observations indicate that the CA:CSA(X) electrolytes may be not suitable for application in hydrogen/oxygen fuel cells, since they are not stable enough to withstand high humidity environments. The materials proposed here remain, however, suitable for other electroactive applications, where they can act as the ion-conducting layer in electrochromic materials or even batteries.

\section{Concluding remarks}

While CSA is widely researched for biomedical applications, seldom work has been done in exploring its applicability as electroactive material. And yet, the presence of sulfonic groups makes it an interesting option for these applications. This study aimed at understanding how CSA could function as a host polymer for PEs.

The combination of CSA with CA afforded materials shown to possess different properties, according to their specific mass ratio: whitish polycrystalline powders at high CA content, or transparent amorphous films at lower CA content. CA is shown to work as a cross-linker, interacting with the anionic groups present in CSA. The optimal CA mass ratio was observed for CA:CSA(60.8), with lower and higher CA mass ratios yielding PEs with worse mechanical properties and lower ionic conductivities.

For $\mathrm{X}=60.8$, SEM and AFM analysis indicated a practically homogenous film with some CA crystallites ranging from 0.88 to $2.6 \mu \mathrm{m}$. An ionic conductivity of about $10^{-7} \mathrm{~S} \mathrm{~cm}^{-1}$ was measured near room temperature. At $50{ }^{\circ} \mathrm{C}, \mathrm{CA}: \mathrm{CSA}(60.8)$ exhibited $10^{-5} \mathrm{~S} \mathrm{~cm}^{-1}$, two orders of magnitude higher than the value observed for CSA. For $\mathrm{RH} \geq 50 \%$ CA:CSA(60.8) displayed higher ionic conductivities than the parent CSA (at $98 \% \mathrm{RH}, 3.7 \times 10^{-2}$ and $3.7 \times 10^{-3} \mathrm{~S} \mathrm{~cm}^{-1}$, respectively).

The results reported here indicate that, although the present systems cannot be directly applied in a hydrogen/oxygen fuel cells, they can still be combined with an inorganic matrix in order to minimize their hydrophility. This study opens interesting prospects of research for CSA-based materials as electrolytes for solid state electrochemical devices, as long as their operation does not lead to the formation of water and does not require ionic conductivities as high as those needed in the case of batteries and fuel cells. Consequently, the present electrolyte system would be suitable, for instance, for electrochemical devices. Moreover, although the materials here reported were obtained by combination of CSA with CA, this strategy could be virtually extended to any combination between an anionic polysaccharide (e.g., CS, hyaluronic acid or heparin) and any carboxylic acid, thereby offering new research possibilities. Indeed variables, such as the number of anionic groups and chemical composition of the monomeric unit, in the case of the polysaccharide, and the number of available protons and the geometry, in the case of the carboxylic acid molecule, can be explored in order to further customize new films.

\section{Data availability}

The raw/processed data required to reproduce these findings cannot be shared at this time as the data also forms part of an ongoing study.

\section{CRediT authorship contribution statement}

Filipe M. Santos: Conceptualization, Investigation, Formal analysis, Writing - original draft, Writing - review \& editing. Paula C. Barbosa: Investigation, Formal analysis, Writing - original draft, Writing - review \& editing. Rui F.P. Pereira: Investigation, Formal analysis, Writing - original draft, Writing - review \& editing. M. Manuela Silva: Supervision, Validation, Writing - original draft, Writing - review \& editing. Helena M.R. Gonçalves: Investigation, Formal analysis, Writing - original draft, Writing - review \& editing. Sílvia C. Nunes: Investigation, Formal analysis, Writing - original draft, Writing - review \& editing. Filipe L. Figueiredo: Visualization, Formal analysis, Supervision, Writing - original draft, Writing - review \& editing, Project administration. Artur J.M. Valente: Investigation, Formal analysis, Validation, Writing - original draft, Writing - review \& editing. Verónica de Zea Bermudez: Visualization, Conceptualization, Supervision, Writing - original draft, Writing - review \& editing, Project administration. 


\section{Declaration of Competing Interest}

The authors declare that they have no known competing financial interests or personal relationships that could have appeared to influence the work reported in this paper.

\section{Acknowledgments}

Support by Fundação para a Ciência e Tecnologia, I.P. (FCT) in the framework of the Strategic Funding UID/FIS/04650/2013, UID/QUI/ $00686 / 2013$, UID/QUI/50006/2019 and UID/QUI/00686/2016. This work was funded by the R\&D Project UniRCell-Unitised regenerative fuel cell for efficient renewable energy supply: from materials to device, with reference POCI-01-0145-FEDER-016422 and SAICTPAC/0032/ 2015, financed by the European Regional Development Fund (ERDF) through COMPETE 2020 - Operational Program for Competitiveness and Internationalization (POCI) and by the Foundation for Science and Technology (FCT) and CICECO-Aveiro Institute of Materials (UID/ CTM/50011/2019), financed by national funds through the FCT/MEC. Is also acknowledged, as well as funding under projects UID/CTM/ 50025/2013, Pest-OE/QUI/UI0616/2014, and LUMECD (PTDC/CTM/ NAN/0956/20149 and POCI-01-0145-FEDER-016884). F. M. Santos acknowledges a Post-PhD Fellow grant supported by Project UniRcell. P. C. Barbosa employment contract is funded by national funds (OE), through FCT - Fundação para a Ciência e a Tecnologia, I.P., in the scope of the framework contract foreseen in the numbers 4,5 and 6 of the article 23, of the Decree-Law 57/2016, of August 29, changed by Law $57 / 2017$, of July 19.R. F. P. Pereira Post-PhD fellow was funded by FCT (SFRH/BPD/87759/2012). S. C. Nunes was funded by FCT projects (Post-PhD Fellowships of UniRCell and LUMECD projects). H.M.R. Gonçalves was funded by NORTE-01-0145-FEDER-030858 and PTDC/ BTM-MAT/30858/2017.

\section{Appendix A. Supplementary material}

Supplementary data to this article can be found online at https:// doi.org/10.1016/j.eurpolymj.2019.109453.

\section{References}

[1] United Nations World Commission on Environment and Development, Brundtland Report: Our Common Future, Oxford University Press, Oxford, 1987.

[2] United Nations, The sustainable development goals report 2016, United Nations, New York, USA, 2016. https://doi.org/10.29171/azu_acku_pamphlet_k3240_s878 2016.

[3] M. Irimia-Vladu, "Green" electronics: biodegradable and biocompatible materials and devices for sustainable future, Chem. Soc. Rev. 43 (2014) 588-610, https://doi. org/10.1039/c3cs60235d.

[4] A. Kafy, H.-U. Ko, H.C. Kim, S. Mun, L. Zhai, J. Kim, Renewable smart materials, 073001 (14p), Smart Mater. Struct. 25 (2016), https://doi.org/10.1088/0964$1726 / 25 / 7 / 073001$.

[5] S. Admassie, F.N. Ajjan, A. Elfwing, O. Inganäs, Biopolymer hybrid electrodes for scalable electricity storage, Mater. Horizons 3 (2016) 174-185, https://doi.org/10. 1039/c5mh00261c.

[6] F.M. Gray, Solid Polymer Electrolytes: Fundamentals and Technological Applications, VCH Publishers Inc, New York, USA, 1991.

[7] C.A.C. Sequeira, D.M.F. Santos, Introduction to Polymer Electrolyte Materials, in: C. A.C. Sequeira, D.M.F. Santos (Eds.), Polym. Electrolytes Fundam. Appl., Woodhead Publishing, Oxford, UK, 2010, pp. 3-61. https://doi.org/10.1533/9781845699772. 1.3 .

[8] P.K. Singh, R.K. Nagarale, S.P. Pandey, H.W. Rhee, B. Bhattacharya, Present status of solid state photoelectrochemical solar cells and dye sensitized solar cells using PEO-based polymer electrolytes, Adv. Nat. Sci. Nanosci. Nanotechnol. 2 (2011) 023002, , https://doi.org/10.1088/2043-6262/2/2/023002 (13p).

[9] A. Kavanagh, R. Byrne, D. Diamond, K.J. Fraser, Stimuli responsive ionogels for sensing applications - an overview, Membranes (Basel) 2 (2012) 16-39, https:// doi.org/10.3390/membranes2010016.

[10] H. Gao, K. Lian, Proton-conducting polymer electrolytes and their applications in solid supercapacitors: a review, RSC Adv. 4 (2014) 33091-33113, https://doi.org/ 10.1039/C4RA05151C.

[11] A. Manthiram, X. Yu, S. Wang, Lithium battery chemistries enabled by solid-state electrolytes, Nat. Rev. Mater. 2 (4) (2017) 16103, , https://doi.org/10.1038/ natrevmats.2016.103 (16p).
[12] V.L. Finkenstadt, Natural polysaccharides as electroactive polymers, Appl. Microbiol. Biotechnol. 67 (2005) 735-745, https://doi.org/10.1007/s00253-0051931-4.

[13] M.J. Neto, F. Sentanin, J.M.S.S. Esperança, M.J. Medeiros, A. Pawlicka, V. de Zea Bermudez, M.M. Silva, Gellan gum - ionic liquid membranes for electrochromic device application, Solid State Ionics 274 (2015) 64-70, https://doi.org/10.1016/j. ssi.2015.02.011.

[14] S.C. Nunes, R.F.P. Pereira, N. Sousa, M.M. Silva, P. Almeida, F.M.L. Figueiredo, V. de Zea Bermudez, Eco-friendly red seaweed-derived electrolytes for electrochemical devices, Adv. Sustain. Syst. 1 (9) (2017) 1700070, https://doi.org/10. 1002/adsu.v1.910.1002/adsu.201700070.

[15] C. Zhong, Y. Deng, A.F. Roudsari, A. Kapetanovic, M.P. Anantram, M. Rolandi, A polysaccharide bioprotonic field-effect transistor (5 pages), Nat. Commun. 2 (2011) 476, , https://doi.org/10.1038/ncomms1489.

[16] J. Ma, Y. Sahai, Chitosan biopolymer for fuel cell applications, Carbohydr. Polym. 92 (2013) 955-975, https://doi.org/10.1016/j.carbpol.2012.10.015.

[17] M.F. Shukur, M.F.Z. Kadir, Electrical and transport properties of $\mathrm{NH}_{4} \mathrm{Br}$-doped cornstarch-based solid biopolymer electrolyte, Ionics (Kiel) 21 (2014) 111-124, https://doi.org/10.1007/s11581-014-1157-5.

[18] M.N. Chai, M.I.N. Isa, Novel proton conducting solid bio-polymer electrolytes based on carboxymethyl cellulose doped with oleic acid and plasticized with glycerol, Sci. Rep. 6 (1) (2016) 27328, , https://doi.org/10.1038/srep27328 (7p.).

[19] F.F. Simas-Tosin, A. Grein-Iankovski, M. Vidotti, I.C. Riegel-Vidotti, Polysaccharides as green biodegradable platforms for building-up electroactive composite materials: an overview, in: V.K. Thakur, M.K. Thakur, M.R. Kessler (Eds. ), Handb. Compos. from Renew. Mater., John Wiley \& Sons, Inc, Beverly, USA, 2017, pp. 377-417. https://doi.org/10.1002/9781119441632.ch97.

[20] A. Takada, J.I. Kadokawa, Fabrication and characterization of polysaccharide ion gels with ionic liquids and their further conversion into value-added sustainable materials, Biomolecules 5 (2015) 244-262, https://doi.org/10.3390/ biom5010244.

[21] T.P. Thuy Pham, C.W. Cho, Y.S. Yun, Environmental fate and toxicity of ionic liquids: a review, Water Res. 44 (2010) 352-372, https://doi.org/10.1016/j.watres. 2009.09.030.

[22] M. Amde, J.F. Liu, L. Pang, Environmental application, fate, effects, and concerns of ionic liquids: a review, Environ. Sci. Technol. 49 (2015) 12611-12627, https://doi. org/10.1021/acs.est.5b03123.

[23] M.E. Heckenbach, F.N. Romero, M.D. Green, R.U. Halden, Chemosphere metaanalysis of ionic liquid literature and toxicology, Chemosphere 150 (2016) 266-274, https://doi.org/10.1016/j.chemosphere.2016.02.029.

[24] M.A. Cardoso, R. Leones, L.C. Rodrigues, M. Fernandes, F.L. Figueiredo, S.C. Nunes, M.M. Silva, V. de Zea Vermudez, Di-ureasil hybrid electrolytes incorporating a new proton ionic liquid, ChemElectroChem. 3 (2016) 783-789, https://doi.org/10. 1002/celc. 201500557.

[25] Q. Zhang, K. De Oliveira Vigier, S. Royer, F. Jérôme, Deep eutectic solvents: syntheses, properties and applications, Chem. Soc. Rev. 41 (2012) 7108-7146, https://doi.org/10.1039/c2cs35178a.

[26] Y. Dai, J. van Spronsen, G.J. Witkamp, R. Verpoorte, Y.H. Choi, Natural deep eutectic solvents as new potential media for green technology, Anal. Chim. Acta 766 (2013) 61-68, https://doi.org/10.1016/j.aca.2012.12.019.

[27] M. Francisco, A. Van Den Bruinhorst, M.C. Kroon, Low-transition-temperature mixtures (LTTMs): a new generation of designer solvents, Angew. Chemie - Int. Ed. 52 (2013) 3074-3085, https://doi.org/10.1002/anie.201207548.

[28] R. Craveiro, I. Aroso, V. Flammia, T. Carvalho, M.T. Viciosa, M. Dionísio, S. Barreiros, R.L. Reis, A.R.C. Duarte, A. Paiva, Properties and thermal behavior of natural deep eutectic solvents, J. Mol. Liq. 215 (2016) 534-540, https://doi.org/10. 1016/j.molliq.2016.01.038.

[29] Y. Liu, J.B. Friesen, J.B. McAlpine, D.C. Lankin, S.N. Chen, G.F. Pauli, Natural deep eutectic solvents: properties, applications, and perspectives, J. Nat. Prod. 81 (2018) 679-690, https://doi.org/10.1021/acs.jnatprod.7b00945.

[30] W.T. Winter, S. Arnott, D.H. Isaac, E.D.T. Atkins, Chondroitin 4-sulfate: the structure of a sulfated glycosaminoglycan, J. Mol. Biol. 125 (1978) 1-19, https://doi. org/10.1016/0022-2836(78)90251-6.

[31] R. Leones, F. Sentanin, S.C. Nunes, J.M.S.S. Esperança, M.C. Gonçalves, A. Pawlicka, V. de Zea Bermudez, M.M. Silva, Effect of the alkyl chain length of the ionic liquid anion on polymer electrolytes properties, Electrochim. Acta 184 (2015) 171-178, https://doi.org/10.1016/j.electacta.2015.09.163.

[32] B. Chakrabarti, J.W. Park, E.S. Stevens, Glycosaminoglycans: structure and interaction, CRC Crit. Rev. Biochem. 8 (1980) 225-313, https://doi.org/10.3109/ 10409238009102572.

[33] R.M. Lauder, Chondroitin sulphate: a complex molecule with potential impacts on a wide range of biological systems, Complement. Ther. Med. 17 (2009) 56-62, https://doi.org/10.1016/j.ctim.2008.08.004.

[34] D.A. Wang, S. Varghese, B. Sharma, I. Strehin, S. Fermanian, J. Gorham, D.H. Fairbrother, B. Cascio, J.H. Elisseeff, Multifunctional chondroitin sulphate for cartilage tissue-biomaterial integration, Nat. Mater. 6 (2007) 385-392, https://doi. org/10.1038/nmat1890.

[35] I.G.F. Gilbert, N.A. Myers, Metal binding properties of chondroitin sulphate, Biochim. Biophys. Acta 42 (1960) 469-475, https://doi.org/10.1016/00063002(60)90825-8.

[36] S. Hirano, C. Mizutani, R. Yamaguchi, O. Miura, Formation of the polyelectrolyte complexes of some acidic glycosaminoglycans with partially N-acylated chitosans, Biopolymers 17 (1978) 805-810, https://doi.org/10.1002/bip.1978.360170320.

[37] A. Denuziere, D. Ferrier, A. Domard, Chitosan-chondroitin sulfate and chitosanhyaluronate polyelectrolyte complexes. Physico-chemical aspects, Carbohydr. Polym. 29 (4) (1996) 317-323, https://doi.org/10.1016/S0144-8617(96)00035-5. 
[38] W. Bin Chen, L.F. Wang, J.S. Chen, S.Y. Fan, Characterization of polyelectrolyte complexes between chondroitin sulfate and chitosan in the solid state, J. Biomed. Mater. Res. - Part A 75 (2005) 128-137, https://doi.org/10.1002/jbm.a.30393.

[39] C. Alvarez-Lorenzo, B. Blanco-Fernandez, A.M. Puga, A. Concheiro, Crosslinked ionic polysaccharides for stimuli-sensitive drug delivery, Adv. Drug Deliv. Rev. 65 (2013) 1148-1171, https://doi.org/10.1016/j.addr.2013.04.016.

[40] C.S. Nunes, K.B. Rufato, P.R. Souza, E.A.M.S. de Almeida, M.J.V. da Silva, D.B. Scariot, et al., Chitosan/chondroitin sulfate hydrogels prepared in [Hmim] $\left[\mathrm{HSO}_{4}\right]$ ionic liquid, Carbohydr. Polym. 170 (2017) 99-106, https://doi.org/10. 1016/j.carbpol.2017.04.073.

[41] S. Yamada, K. Sugahara, Potential therapeutic application of chondroitin sulfate/ dermatan sulfate, Curr. Drug Discov. Technol. 5 (2008) 289-301, https://doi.org/ $10.2174 / 157016308786733564$.

[42] A. Köwitsch, G. Zhou, T. Groth, Medical application of glycosaminoglycans: a review, J. Tissue Eng. Regen. Med. 12 (2018) e23-e41, https://doi.org/10.1002/ term. 2398.

[43] Y. Li, J. Rodrigues, H. Tomás, Injectable and biodegradable hydrogels: gelation, biodegradation and biomedical applications, Chem. Soc. Rev. 41 (2012) 2193-2221, https://doi.org/10.1039/c1cs15203c.

[44] R. Ciriminna, F. Meneguzzo, R. Delisi, M. Pagliaro, Citric acid: emerging applications of key biotechnology industrial product, Chem. Central J. 11 (1) (2017) 22, , https://doi.org/10.1186/s13065-017-0251-y (9p.).

[45] M. Espino, M. de los Ángeles Fernández, F.J.V. Gomez, M.F. Silva, Natural designer solvents for greening analytical chemistry, TrAC - Trends Anal. Chem. 76 (2016) 126-136, https://doi.org/10.1016/j.trac.2015.11.006.

[46] P. Jia, H. Xia, K. Tang, Y. Zhou, Plasticizers derived from biomass resources: a short review, 1303 (27 pp), Polymers (Basel) 10 (2018), https://doi.org/10.3390/ polym 10121303.

[47] Y. Yang, H. Gao, L. Zheng, Anhydrous proton exchange membranes at elevated temperatures: effect of protic ionic liquids and crosslinker on proton conductivity, RSC Adv. 5 (2015) 17683-17689, https://doi.org/10.1039/c4ra16106h.

[48] I.A. Fadzallah, S.R. Majid, M.A. Careem, A.K. Arof, A study on ionic interactions in chitosan-oxalic acid polymer electrolyte membranes, J. Memb. Sci. 463 (2014) 65-72, https://doi.org/10.1016/j.memsci. 2014.03.044.

[49] I.A. Fadzallah, I.M. Noor, M.A. Careem, A.K. Arof, Investigation of transport properties of chitosan-based electrolytes utilizing impedance spectroscopy, Ionics (Kiel) 22 (2016) 1635-1645, https://doi.org/10.1007/s11581-016-1687-0.

[50] E. Prokhorov, G. Luna-Bárcenas, J.B. González-Campos, Y. Kovalenko, Z.Y. GarcíaCarvajal, J. Mota-Morales, Proton conductivity and relaxation properties of chitosan-acetate films, Electrochim. Acta 215 (2016) 600-608, https://doi.org/10. 1016/j.electacta.2016.08.148.

[51] Y. Zhao, Z. Jiang, L. Xiao, T. Xu, S. Qiao, H. Wu, Chitosan membranes filled with biomimetic mineralized hydroxyapatite for enhanced proton conductivity, Solid State Ionics 187 (2011) 33-38, https://doi.org/10.1016/j.ssi.2011.01.019.

[52] B. Larsson, M. Nilsson, H. Tjälve, The binding of inorganic and organic cations and $\mathrm{H}^{+}$to cartilage in vitro, Biochem. Pharmacol. 30 (1981) 2963-2970, https://doi. org/10.1016/0006-2952(81)90260-4.

[53] A.M.N. Silva, X. Kong, R.C. Hider, Determination of the pKa value of the hydroxyl group in the $\alpha$-hydroxycarboxylates citrate, malate and lactate by ${ }^{13} \mathrm{C}$ NMR: implications for metal coordination in biological systems, BioMetals 22 (2009) 771-778, https://doi.org/10.1007/s10534-009-9224-5.

[54] C.Y. Wong, W.Y. Wong, R.G. Walvekar, K.S. Loh, M. Khalid, K.L. Lim, Effect of deep eutectic solvent in proton conduction and thermal behaviour of chitosan-based membrane, J. Mol. Liq. 269 (2018) 675-683, https://doi.org/10.1016/j.molliq. 2018.08.102.

[55] J.F. Piai, L.C. Lopes, A.R. Fajardo, A.F. Rubira, E.C. Muniz, Kinetic study of chon droitin sulphate release from Chondroitin sulphate/chitosan complex hydrogel, J. Mol. Liq. 156 (2010) 28-32, https://doi.org/10.1016/j.molliq.2010.05.017.

[56] S.M. Best, M.J. Duer, D.G. Reid, E.R. Wise, S. Zou, Towards a model of the mineralorganic interface in bone: NMR of the structure of synthetic glycosaminoglycanand polyaspartate-calcium phosphate composites, Magn. Reson. Chem. 46 (2008) 323-329, https://doi.org/10.1002/mrc. 2168.

[57] V.H. Pomin, NMR chemical shifts in structural biology of glycosaminoglycans, Anal. Chem. 86 (2014) 65-94, https://doi.org/10.1021/ac401791h.

[58] J.W. Fischer, L.H. Merwin, R.A. Nissan, NMR investigation of the thermolysis of citric acid, Appl. Spectrosc. 49 (1995) 120-126, https://doi.org/10.1366/ 0003702953963229.

[59] J.W. Mullin, C.L. Leci, Evidence of molecular cluster formation in supersaturated solutions of citric acid, Philos. Mag. 19 (1969) 1075-1077, https://doi.org/10. 1080/14786436908225872.

[60] G.K. Hamer, A.S. Perlin, A ${ }^{13}$ C-N.M.R. spectral study of chondroitin sulfates A, B and C: evidence of heterogeneity, Carbohydr. Res. 49 (1976) 37-48, https://doi
org/10.1016/S0008-6215(00)83123-7.

[61] S.M. Bociek, A.H. Darke, D. Welti, D.A. Rees, The ${ }^{13}$ C-NMR spectra of hyaluronate and chondroitin sulphates: further evidence on an alkali-induced conformation change, Eur. J. Biochem. 109 (1980) 447-456, https://doi.org/10.1111/j.14321033.1980.tb04814.x.

[62] J. Schiller, L. Naji, D. Huster, J. Kaufmann, K.A. Arnold, ${ }^{1} \mathrm{H}$ and ${ }^{13} \mathrm{C}$ HR-MAS NMR investigations on native and enzymatically digested bovine nasal cartilage, MAGMA 13 (2001) 19-27, https://doi.org/10.1007/BF02668647.

[63] A.R. Fajardo, J.F. Piai, A.F. Rubira, E.C. Muniz, Time- and pH-dependent self-rearrangement of a swollen polymer network based on polyelectrolytes complexes of chitosan/chondroitin sulfate, Carbohydr. Polym. 80 (2010) 934-943, https://doi. org/10.1016/j.carbpol.2010.01.009.

[64] M. Criado, J.M. Rey, C. Mijangos, R. Hernández, Double-membrane thermoresponsive hydrogels from gelatin and chondroitin sulphate with enhanced mechanical properties, RSC Adv. 6 (2016) 105821-105826, https://doi.org/10.1039/ c6ra25053j.

[65] A.L. Kolesnikov, Y.A. Budkov, E.A. Nogovitsyn, Coarse-grained model of glycosaminoglycans in aqueous salt solutions. A field-theoretical approach, J. Phys. Chem. B 118 (2014) 13037-13049, https://doi.org/10.1021/jp503749a.

[66] E.A. Nogovitsin, Yu.A. Budkov, Self-consistent field theory investigation of the behavior of hyaluronic acid chains in aqueous salt solutions, Physica A 391 (2012) 2507-2517, https://doi.org/10.1016/j.physa.2011.12.040.

[67] R. Anedda, C. Cannas, A. Musinu, G. Pinna, G. Piccaluga, M. Casu, A two-stage citri acid-sol/gel synthesis of $\mathrm{ZnO} / \mathrm{SiO}_{2}$ nanocomposites: study of precursors and final products, J. Nanoparticles Res. 10 (2008) 107-120, https://doi.org/10.1007/ s11051-007-9235-5.

[68] S. Brézillon, V. Untereiner, L. Lovergne, I. Tadeo, R. Noguera, F.X. Maquart, Y. Wegrowski, G.D. Sockalingum, Glycosaminoglycan profiling in different cell types using infrared spectroscopy and imaging, Anal. Bioanal. Chem. 406 (2014) 5795-5803, https://doi.org/10.1007/s00216-014-7994-2.

[69] S.F.D. Orr, Infra-red spectroscopic studies of some polysaccharides, Biochim Biophys. Acta 14 (1954) 173-181, https://doi.org/10.1016/0006-3002(54) 90156-0.

[70] J.J. Cael, D.H. Isaac, J. Blackwell, J.L. Koenig, E.D.T. Atkins, J.K. Sheehan, Polarized infrared spectra of crystalline glycosaminoglycans, Carbohydr. Res. 50 (1976) 169-179, https://doi.org/10.1016/S0008-6215(00)83848-3.

[71] B. Casu, A.J. Cifonelli, A.S. Perlin, Infrared spectra of glycosaminoglycans in deuterium oxide and deuterium chloride solution: quantitative evaluation of uronic acid and acetamidodeoxyhexose moieties, Carbohydr. Res. 63 (1978) 13-27, https://doi.org/10.1016/S0008-6215(00)80925-8.

[72] R. Servaty, J. Schiller, H. Binder, K.A. Arnold, Hydration of polymeric component of cartilage - an infrared spectroscopic study on hyaluronic acid and chondroitin sulfate, Int. J. Biol. Macromol. 28 (2001) 121-127, https://doi.org/10.1016/ S0141-8130(00)00161-6.

[73] C. Djordjevic, M. Lee, E. Sinn, Oxoperoxo(citrato)- and dioxo(citrato)vanadates(V): synthesis, spectra, and structure of a hydroxyl oxygen bridged dimer $\mathrm{K}_{2}\left[\mathrm{VO}\left(\mathrm{O}_{2}\right)\right.$ $\left.\left(\mathrm{C}_{6} \mathrm{H}_{6} \mathrm{O}_{7}\right)\right]_{2} \cdot 2 \mathrm{H}_{2} \mathrm{O}$, Inorg. Chem. 380 (1989) 719-723, https://doi.org/10.1021/ ic00303a022.

[74] P. Tarakeshwar, S. Manogaran, Ground state vibrations of citric acid and the citrate trianion - an ab initio study, Spectrochim. Acta Part A Mol. Spectrosc. 50 (1994) 2327-2343, https://doi.org/10.1016/0584-8539(94)E0017-5.

[75] S.A. Brandán, L.C. Bichara, H.E. Lans, E.G. Ferrer, M.B. Gramajo, Vibrational study and force field of the citric acid dimer based on the SQM methodology, Adv. Phys. Chem. 2011 (2011) 347072, , https://doi.org/10.1155/2011/347072 (10p.).

[76] J.F. Piai, A.F. Rubira, E.C. Muniz, Self-assembly of a swollen chitosan/chondroitin sulfate hydrogel by outward diffusion of the chondroitin sulfate chains, Acta Biomater. 5 (2009) 2601-2609, https://doi.org/10.1016/j.actbio.2009.03.035.

177] A.R. Fajardo, L.C. Lopes, A.J.M. Valente, A.F. Rubira, E.C. Muniz, Effect of stoichiometry and $\mathrm{pH}$ on the structure and properties of chitosan/chondroitin sulfate complexes, Colloid Polym. Sci. 289 (2011) 1739-1748, https://doi.org/10.1007/ s00396-011-2497-6.

[78] M. Bathe, G.C. Rutledge, A.J. Grodzinsky, B. Tidor, A coarse-grained molecular model for glycosaminoglycans: application to chondroitin, chondroitin sulfate, and hyaluronic acid, Biophys. J. 88 (2005) 3870-3887, https://doi.org/10.1529/ biophysj.104.058800.

[79] N. Volpi, A. Mucci, L. Schenetti, Stability studies of chondroitin sulfate, Carbohydr. Res. 315 (1999) 345-349, https://doi.org/10.1016/S0008-6215(99)00034-8.

[80] T. Gümüşoĝlu, G.A. Ari, H. Deligöz, Investigation of salt addition and acid treatment effects on the transport properties of ionically cross-linked polyelectrolyte complex membranes based on chitosan and polyacrylic acid, J. Memb. Sci. 376 (2011) 25-34, https://doi.org/10.1016/j.memsci.2011.03.040. 